\title{
Animal model studies of genital chlamydial infections Immunity to re-infection with guinea-pig inclusion conjunctivitis agent in the urethra and eye of male guinea-pigs
}

\author{
L. V. HOWARD, M. P. O'LEARY, AND R. L. NICHOLS \\ Center for Study of Sexually Transmitted Diseases, Department of Microbiology, \\ Harvard School of Public Health, Boston, Mass.
}

\begin{abstract}
Summary
A previous report demonstrated that male guineapigs could be infected in the urethra with guinea-pig inclusion conjunctivitis (GPIC) agent and that the infection was transmitted during mating from infected males to females. In the experiments reported here, inoculation of male guinea-pigs in the urethra with GPIC organisms resulted in infection which subsided spontaneously in about 2 weeks. Males were demonstrated to be completely resistant to urethral challenge with $10^{3} \mathrm{ID}_{50}$ when tested 6 weeks after urethral infection. These guinea-pigs, immune to re-infection of the urethra, remained susceptible to infection of the eye, but this ocular infection was shorter in duration than that in previously uninfected control animals. Infection in the eye resulted in immunity to both ocular and urethral infection when animals were challenged 6 weeks after the ocular infection.
\end{abstract}

\section{Introduction}

Chronic urethritis in the human genital tract associated with inclusion-forming agents was first described by Halberstaedter and von Prowazek (1909) and later by Lindner (1910). Granulations or follicles of the male urethra were scraped and yielded cells with inclusions which were thought to be viral in nature. T'ang, Chang, Huang, and Wang (1957) developed methods for the isolation of the trachoma agent from cases of conjunctivitis with inclusions after which understanding of the nature of infections with Chlamydia trachomatis developed rapidly (Collier, Duke-Elder, and Jones, 1958; Jawetz, Rose, Hanna, and Thygeson, 1965; Nichols and McComb, 1964). Chlamydia are responsible for several important infections in man, including trachoma and lympho-

Received for publication December 9, 1975

Address for reprints: R. L. Nichols, M.D., Department of Microbiology, 665 Huntington Avenue, Boston, Mass. 02115, U.S.A. granuloma venereum. Members of the genus Chlamydia are intracellular parasitic bacteria with a unique life cycle (Moulder, 1966).

Jones, Collier, and Smith (1959) were the first to isolate a strain of Chlamydia from the cervix of a mother whose baby had inclusion-positive ophthalmitis neonatorum and from the eyes of another such baby. Isolation of Chlamydia from a man with urethritis was accomplished in the same laboratory (Jones, Al-Hussaini, and Dunlop, 1964), thereby initiating modern research into the role(s) these agents may play in non-gonococcal urethritis (NGU). Since these pioneering studies, it has been established that many cases of urethritis in men are nongonococcal in origin, and that $C$. trachomatis strains are recoverable from about 40 per cent. of cases of NGU (Dunlop, Jones, Darougar, and Treharne, 1972). Evidence for a role of $C$. trachomatis in this disease and for sexual transmission of this agent is accumulating (Holmes, Handsfield, Wang, Wenworth, Turck, Anderson, and Alexander, 1975).

Animal models with natural infection of the genital tract by sexually transmissible agents have not yet been developed to the knowledge of the authors. Chimpanzees have been infected with Neisseria gonorrhoeae isolated from man, and have transmitted the disease sexually (Lucas, Chandler, Martin, and Smale, 1971); however, gonorrhoea is not known to be an infection indigenous to chimpanzees. A good animal model for sexually transmitted infections may yield information on the dynamics of transmission, mechanisms of resistance, methods for prevention of transmission, development of immunity through use of vaccines, and efficacy of prophylaxis or treatment.

The infection of guinea-pigs by guinea-pig inclusion conjunctivitis (GPIC) agent was discovered and developed as an animal model for chlamydial infections of the eye by Dr. E. S. Murray in this laboratory (Murray, 1964; Murray, Charbonnet, and MacDonald, 1973). Mount, Bigazzi, and Barron (1972, 1973), who were the first to study infections of the genital tract of female and male guinea-pigs with 
GPIC agent, reported sexual transmission from male to female animals. Transmission of GPIC from males to females during mating has been confirmed (Howard, O'Leary, and Nichols, unpublished data).

This paper describes development of immunity to re-infection with GPIC in animals that have recovered from urethral or conjunctival infection by GPIC organism.

\section{Material and methods}

\section{Experimental animals}

Hartley strain guinea-pigs weighing 500 to 750 g., from a herd which has been maintained free of the GPIC agent for the past 9 years, were used.

\section{Inocula and procedure of infection}

Inocula of GPIC organisms, grown in the yolk sac of chicken embryos, were stored sealed in glass ampoules at $-80^{\circ} \mathrm{C}$. as a 50 per cent. suspension in $0.1 \mathrm{ml}$ quantities. Each inoculum was thawed only once, 1 to $2 \mathrm{hrs}$ before use, and diluted 10-fold serially with phosphate glutamate sucrose (Bovarnick, Miller, and Snyder, 1950). Initially animals were anaesthetized with ether before inoculation. In later experiments, sodium pentobarbital $50 \mathrm{mg} / \mathrm{ml}$ was used; animals were injected intraperitoneally with $0.06 \mathrm{ml}$. per $100 \mathrm{~g}$. body weight.

Infection was produced in male guinea-pigs by inoculating the urethra of the extruded penis with $0.05 \mathrm{ml}$. of a dilution of GPIC agent, using a sterile glass $0.25 \mathrm{ml}$. syringe and a blunted 21 gauge needle. $2 \mathrm{~cm}$. of vinyl tubing, $0.06 \mathrm{~cm}$. in diameter, was slipped over the needle to prevent damage to the urethra. In each test for immunity the inoculum used for challenge was simultaneouly titrated in the eye or urethra of uninfected guinea-pigs. Challenge doses are expressed as infectious dose $50\left(\mathrm{ID}_{50}\right)$.

\section{Detection of infection and antibody response}

The urethra of each anaesthetized animal was scraped between 4 and 21 days after inoculation with a dental spatula (S.S. White, 'Tarno WDS 2'). Smears were fixed in methanol and stained by Giemsa's method. No less than 200 cells were counted. Inclusions were recorded as the number of infected cells per 100 cells examined over a wide area of the smeared specimen.

Blood was taken from the guinea-pigs by cardiac puncture before inoculation and during the course of the infection. Sera were stored at $-20^{\circ} \mathrm{C}$. and antibody titres obtained by an immunofluorescence technique. A threelayered indirect test was used: first layer, antigen; second layer, guinea-pig sera; third layer, rabbit antiguinea-pig sera conjugated with fluorescein isothiocyanate (Murray, and others, 1973).

\section{Results}

Intensity and duration of urethral infection in male guinea-pigs and establishment of infectious dose 50

Male animals that had not been infected before were inoculated in the urethra with 10 -fold serial dilutions of infected yolk sac. Urethral scrapings were examined on Days 6, 8, 14, and 21 after inoculation to determine the intensity and duration of the disease. All animals became infected when inoculated with $10^{-1}$ to $10^{-4}$ dilutions of the standard yolk sac pool (Table I). The infection had usually subsided by Day 14. No inclusion was seen in urethral cells 21 days after inoculation. In a second independent titration, all animals were infected except one receiving the $10^{-5}$ dilution and in a third titration all animals were infected at dilutions up to $10^{-5}$ (data not shown). Thus, male animals were reproducibly infected in the urethra and infection could be satisfactorily monitored by counting inclusions in scrapings of urethral cells.

When animals were challenged with the $10^{-2}$ dilution which was routinely used in tests for immunity, infection was detected in most of them 4 days after inoculation. Therefore, in later experiments, urethral material was obtained by scraping on Days 4, 7, and 14. As with the observations of Mount, Bigazzi, and Barron (1973), polymorphonulear leucocytes were present in urethral scrapings from infected but not from uninfected guinea-pigs.

\section{Immunity in the urethra after urethral infection}

Fifteen male guinea-pigs designated as test animals were inoculated in the urethra. Eyes were scraped twice a week to rule out accidental infection of the eye which could result in an immunological response unrelated to the urethral infection. Two of the fifteen had accidental infections of the eye and the data for these animals are presented separately.

The thirteen remaining test animals were challenged 42 days after the primary inoculation with a dose of $10^{3} \mathrm{ID}_{50}$ calculated from a simultaneous titration in the urethra of previously uninfected males. No inclusion was found in material from any of the thirteen previously infected animals on Days 4, 7, and 14 after challenge (Table II). In contrast, control animals receiving the same inoculum had average inclusion rates of 15,8 , and less than 1 per cent. on Days 4, 7, and 14 respectively.

Further evidence that previously infected animals

TABLE I Infection of male urethras with varying doses of GPIC

\begin{tabular}{|c|c|c|c|c|c|}
\hline \multirow{2}{*}{$\begin{array}{l}\text { Dilution of GPIC } \\
\text { inoculum }\end{array}$} & \multicolumn{4}{|c|}{ Average number of inclusions per 100 cells } & \multirow{2}{*}{$\frac{\text { No. infected }}{\text { No. challenged }}$} \\
\hline & Day 6 & Day 8 & Day 14 & Day 21 & \\
\hline $10^{-1}$ & 10 & 6 & 0 & 0 & $2 / 2$ \\
\hline $10^{-3}$ & 1 & 11 & 0 & 0 & $2 / 2$ \\
\hline $10^{-4}$ & 0 & 5 & 0 & 0 & $2 / 2$ \\
\hline $10^{-5}$ & 0 & 8 & 0 & 0 & $1 / 2$ \\
\hline
\end{tabular}


TABLE II Test for immunity to urethral infection in guinea-pigs previously infected in the urethra

\begin{tabular}{|c|c|c|c|c|c|c|c|}
\hline \multirow{2}{*}{\multicolumn{3}{|c|}{$\begin{array}{l}\text { First urethral inoculation } \\
\text { Percent. cells infected on days after inoculation }\end{array}$}} & \multicolumn{5}{|c|}{ Second urethral inoculation ${ }^{\mathrm{a}}$} \\
\hline & & & \multirow{2}{*}{$\begin{array}{l}\text { Number of } \\
\text { days after } \\
\text { first urethral } \\
\text { inoculation }\end{array}$} & \multicolumn{3}{|c|}{ Percent. cells infected on days after inoculation } & \multirow[b]{2}{*}{$\begin{array}{l}\text { No. infected } \\
\text { No. challenged }\end{array}$} \\
\hline Day 4 & Day 7 & Day 14 & & Day 4 & Day 7 & Day 14 & \\
\hline 4 & 6 & $<1$ & $\begin{array}{l}42 \\
\text { Controls }\end{array}$ & $\begin{array}{r}0 \\
15\end{array}$ & $\begin{array}{l}0 \\
8\end{array}$ & $\begin{array}{r}0 \\
<1\end{array}$ & $\begin{array}{l}0 / 13 \\
4 / 4\end{array}$ \\
\hline
\end{tabular}

Challenge dose $10^{3} \mathrm{ID}_{50}$

were not reinfected after challenge was obtained by monitoring the serum antibody titres of test animals for evidence of an anamnestic response. In test animals the geometric mean of the serum antibody titres was $1 / 58$ immediately before the second urethral inoculation, and 2 weeks after the second urethral inoculation (Day 56) the titre was 1/20. This suggested that the test animals had not received an antigenic stimulus resulting in a rise in antibody titre, which we observed routinely after infection of the eye or urethra in control animals. In the test animals polymorphonuclear leucocytes were rarely seen in urethral scrapings, in contrast to those of infected control animals in which leucocytes were numerous.

\section{Immunity in the eye after urethral infection}

The thirteen test animals used in the previous experiment were tested for immunity to conjunctival infection 56 days after urethral infection and 14 days after the second urethral inoculation. All of the thirteen animals became infected in the eye after challenge. There was no significant difference (Student's $t$ test) in the numbers of inclusions between test and control animals on Days 4 and 7 (Table III). On Day 11, all but one of the thirteen test animals were inclusion-negative (rate of less than 1 per cent.) while the control animals contiued to have high inclusion rates (range 11 to 17 per cent.). On this day the difference between the number positive in the test group (1/13) and in the control group (3/3) was significant as determined by Fisher's exact test $(P<0.01) .2$ weeks after challenge of the eye the serum antibody titre had risen from $1 / 20$ to $1 / 122$ in the test group.

In a repeat of this experiment all of five animals were immune to challenge in the urethra 42 days after urethral infection. 2 weeks after urethral immunity was demonstrated, all five guinea-pigs became infected in the conjunctiva after challenge of the eye.

In the two experiments presented here, a total of seven animals, had accidental infection of the eye soon after inoculation of the urethra. Nevertheless, these animals were challenged in the eye in the same manner as those which were infected only in the urethra. In contrast to the animals with previous urethral infection only, none of these seven animals, accidentally infected in the eye, developed conjunctival cell inclusions when challenged in the eye 56 days after the urethral infection.

Immunity in the urethra after infection of the eye Nine male guinea-pigs were inoculated in the eye with a dose of $10^{3} \mathrm{ID}_{50}$ and infection was verified by observing inclusions in eye scrapings. None of these guinea-pigs developed accidental urethral infection while infected in the eye or for a period of 42 days thereafter. 42 days after inoculation of the eye, animals were challenged in the urethra. None of the nine animals had inclusions in urethral cells obtained on Day 4 (Table IV). Four of these nine animals died before Day 7 because of causes unrelated to infection with GPIC agent. On Days 7 and 14 all of the five remaining animals were inclusion-free. In contrast, all seven control animals which received an identical inoculum became infected. Further evidence for lack of infection in experimental animals was the observation that the mean serum antibody titre remained unchanged at $1 / 80$ between the time of challenge and 2 weeks after challenge, indicating the absence of a booster effect. In addition, leucocytes were seen only occasionally in scrapings of urethral material from test animals on Days 4,7, and 14.

TABLE III Test for immunity to infection of the eye in male guinea-pigs previously infected in the urethra

\begin{tabular}{|c|c|c|c|c|c|}
\hline $\begin{array}{l}\text { No. of days between primary } \\
\text { urethral infection and eye } \\
\text { challenge }\end{array}$ & \multicolumn{4}{|c|}{ Average number of inclusions per 100 cells } & $\begin{array}{l}\text { No. } \text { infected } \\
\text { No. challenged }\end{array}$ \\
\hline $\begin{array}{l}56 \\
\text { Controls }\end{array}$ & $\begin{array}{l}12 \\
16\end{array}$ & $\begin{array}{l}3 \\
5\end{array}$ & $\begin{array}{l}<1 \\
14\end{array}$ & $\begin{array}{l}<1 \\
<1\end{array}$ & $\begin{array}{c}13 / 13 \\
3 / 3\end{array}$ \\
\hline
\end{tabular}

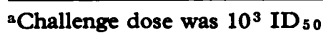


TABLE IV Test for immunity to urethral infection in guinea-pigs previously infected in the eye

\begin{tabular}{|c|c|c|c|c|c|c|c|}
\hline \multirow{2}{*}{\multicolumn{3}{|c|}{$\frac{\text { Eye inoculation }}{\text { Percentage cells infected on days after inoculation }}$}} & \multicolumn{5}{|c|}{ Subsequent urethral inoculation ${ }^{\mathrm{a}}$} \\
\hline & & & \multirow{2}{*}{$\begin{array}{l}\text { No. of days } \\
\text { after eye } \\
\text { inoculation }\end{array}$} & \multicolumn{3}{|c|}{ Percentage cells infected on days after inoculation } & \multirow{2}{*}{$\frac{\text { No. infected }}{\text { No. challenged }}$} \\
\hline Day 4 & Day 7 & Day 11 & & Day 4 & Day 7 & Day 14 & \\
\hline 17 & 6 & 12 & $\begin{array}{l}42 \\
\text { Controls }\end{array}$ & $\begin{array}{l}0^{b} \\
5\end{array}$ & $\begin{array}{l}0 \\
6\end{array}$ & $\begin{array}{l}0 \\
0\end{array}$ & $\begin{array}{l}0 / 5 \\
7 / 7\end{array}$ \\
\hline
\end{tabular}

aChallenge dose was $10^{3} \mathrm{ID}_{50}$

b0/9 were positive on Day 4. Four animals died between Days 4 and 7

\section{Discussion}

Previous studies demonstrated that GPIC agent caused disease of the eye and genital tract due to local infection of epithelial cells (Murray, 1964; Mount and others, 1973). The present studies were designed to investigate immunity to infection with GPIC agent in the urethra of previously infected male guinea-pigs. To examine the possibility that immunity was local, animals were infected at one anatomical site, the urethra, and then tested for immunity at a distant site, the conjunctiva. In further experiments, animals were infected in the conjunctiva and later tested for immunity in the urethra.

Immunity to urethral infection after infection at the same site was clearly demonstrated in each of thirteen test animals. When this experiment was repeated (data not presented), all of five test guineapigs were immune. No inclusion was seen in any animals after challenge, indicating that immunity was complete. In addition, no increase in serum antibody titre was detected and few leucocytes were seen in urethral scrapings of these animals. However, when these guinea-pigs were challenged in the eye with an identical inoculum, all thirteen test animals were found to be susceptible to infection of the eye, although the infection was of short duration compared to that of previously uninfected animals.

Immunity in the eye after infection with GPIC agent has been reported by Murray and others, 1973). In the present experiments in which guineapigs were infected accidentally in the eye, immunity to conjunctival infection was also observed. When initial infection of the eye was followed by challenge in the male urethra, animals were immune to urethral infection. Thus, immunity in guinea-pigs to infection with GPIC appears not to be an entirely local phenomenon. We have demonstrated that infection of the eye leads to fully protective immunity of the eye and urethra, whereas urethral infection results in fully protective urethral immunity but weak immunity of the eye. The explanation for this observation awaits further information on the mechanism of immunity to infection with GPIC agent.

Studies by Murray and his colleagues (unpublished data) indicate:

(1) That a GPIC eye infection produces strong immunity against re-infection in either the eye or the vagina; (2) That while a vaginal infection due to GPIC agent produces strong immunity against vaginal re-infection, it produces only moderate or partial immunity to re-infection of the conjunctiva.

The possibility of cross-infection between different areas of the body presents a difficulty in studying the influence of infection at one anatomical site on the development of immunity at another site. In our studies, when males were infected in the urethra eyes were scraped twice a week to detect accidental eye infection. It is unlikely that there was an undetected infection of the eye in any of the thirteen animals discussed in Table II, since these animals were still susceptible to infection of the eye after challenge. These animals appeared to be a homogeneous group, in that all thirteen had relatively high inclusion rates. In contrast, the animals which suffered accidental infection of the eye by GPIC agent were subsequently immune in the eye. In the experiment in which animals were first infected in the eye and then challenged in the urethra, no accidental urethral infections were detected. Again these animals appeared to be a homogeneous group in that all were completely immune to urethral infection. It is unlikely that all had an undetected urethral infection.

The immunity to infections of urethra and eye may be dependent on the challenge dose and on the interval between infection and subsequent challenge. In the present experiments, immunity to urethral infection was demonstrated after a challenge dose of approximately $10^{3} \mathrm{ID}_{50}$. It is possible that a greater challenge dose would overcome immunity. Further information is needed on the number of infectious doses transmitted during the mating of infected animals. All animals were challenged 6 to 8 weeks after infection of the eye which is the time of complete immunity to re-infection in the eye (Murray and others, 1973). Male animals may show a waning of immunity when tested at longer intervals of time after the initial infection. This lessening of immunity may appear as a difference in inclusion rates or in the number of infectious doses necessary to infect animals.

The demonstration of immunity to this chlamydial infection in the urethra of male guinea-pigs provides 
an opportunity to study the mechanism of immunity to genital tract infections by Chlamydia. Further development of this animal model for the study of sexually transmitted disease due to Chlamydia may lead to vaccination regimes and diagnostic techniques applicable to these diseases in man. Resistance to infection in males alone may be sufficient to disrupt the sexual transmission of chlamydial agents.

The authors thank Al Grimshaw for assistance with animals used in these experiments.

\section{References}

Bovarnick, M. R., Miller, J. C., and SNYDER, J. C. (1950) F. Bact., 59, 509

Collier, L. H., DUKe-Elder, S., and JoNes, B. R. (1958) Brit. F. Ophthal., 42, 705

Dunlop, E. M. C., Jones, B. R., Darougar, S., and TreHARne, J. D. (1972) Brit. med. f., 2, 575

Halberstaedter, L., and Prowazek, S. von (1909) Berl. klin. Wschr., 46, 1839
Holmes, K. K., Handsfield, H. H., Wang, S. P., Wentworth, B. B., Turck, M., ANDERson, J. B., and Alexander, E. R. (1975) New Engl. f. Med., 292, 1199

Jawetz, E., Rose, L., Hanna, L., and Thygeson, P. (1965) f. Amer. med. Ass., 194, 620

Jones, B. R., Al-Hussaini, M. K., and Dunlop, E. M. C. (1964) Brit. F. vener. Dis., 40, 19

, Collier, L. H., and SMITH, C. H. (1959) Lancet, 1, 902

LINDNER, K. (1910) Wien. klin. Wschr., 23, 283

LuCAS, C. T., Chandler, F., Jr., Martin, J. E., Jr., Schmale, J. D. (1971) F. Amer. med. Ass., 216, 1612

MOULDER, J. W. (1966) Ann. rev. Microbiol., 20, 107

Mount, D. T., Bigazzi, P. E., and BARron, A. L. (1972) Infect. and Immun., 5, 921

$\longrightarrow,-,-$ (1973) Ibid., 8, 925

MurRay, E. S. (1964) F. infect. Dis., 114, 1

, Charbonnet, L. L., and MacDonald, A. B. (1973) f. Immunol., 110, 1518

Nichols, R. L., and MсСомв, D. E. (1964) f. exp. Med., 120,639

T'ANG, F. F., Chang, H. L., Huang, Y. T., and Wang, K. C. (1957) Chin. med. F., 75, 429 